Special Issue of the 6th International Congress \& Exhibition (APMAS2016), Maslak, Istanbul, Turkey, June 1-3, 2016

\title{
Soda Lime Silicate Glass-to-Titanium Joining by Controlled Heat Treatments in Air
}

\begin{abstract}
M.B. TELLi*
Kocaeli University, Department of Metallurgical and Materials Engineering, 41380 Kocaeli, Turkey

Glass-to-metal joining is important for improving efficiencies of heat collecting units, employed in parabolic solar collecting systems. In this study, soda lime silicate glass was joined to titanium in air at 700,800 and $900{ }^{\circ} \mathrm{C}$ for $5 \mathrm{~min}$ by controlled heat treatments. Glass-to-titanium bonding was good and no delamination or macro cracking in glass was observed. During heat treatment, titanium is oxidized in air prior to the reaction with glass. The reaction between oxidized titanium and glass results in bubble formation at joining interface. Bubble formation was found to be decreased with decreasing joining temperature. Thermal stresses developed at glass-titanium junction were modeled by employing ANSYS 14 multiphysics simulation software. For the studied sample profile, soda lime silicate glass, close to the joining interface, experienced rather low residual stresses of the order of $10 \mathrm{MPa}$ maximum and $-40 \mathrm{MPa}$ minimum principal stress levels. Good glass-to-titanium bonding and low thermal residual stress are mainly due to similar thermal expansion coefficients of these materials, which was found to be important for achieving successful joining in air.
\end{abstract}

DOI: 10.12693/APhysPolA.131.414

PACS/topics: $81.20 . \mathrm{Vj}$

\section{Introduction}

Glass-to-metal joining is required for a wide range of applications including vacuum insulation glazing, electrical discharge tubes, vacuum solar collectors and glass encapsulated diodes [1]. For parabolic solar collector systems, a good and reliable glass-metal junction is important for improving energy efficiencies of heat collecting units [2]. Heat collecting element is made of a metal pipe, to carry solar heated fluid and a glass tube, to thermally insulate the heated metal pipe. Borosilicate glasskovar alloy joining is often considered due to their closely matched thermal expansion coefficients [2-4]. However, kovar alloy is rather expensive and if soda lime silicate glass-to-titanium joining is achieved, it could be an economical alternative for borosilicate glass-to-kovar alloy joining. Soda lime silicate glass is an economical glass, commonly used for outdoor applications [5]. Titanium is more economical compared to kovar alloy and has good corrosion resistance and is employed for high temperature applications, requiring mechanical integrity [6]. In addition, titanium has close value of thermal expansion coefficient $\left(10.1 \times 10^{-6}(\mathrm{~m} / \mathrm{m}) /{ }^{\circ} \mathrm{C}\right)$ to that of soda lime silicate glass $\left(9.1 \times 10^{-6}(\mathrm{~m} / \mathrm{m}) /{ }^{\circ} \mathrm{C}\right)$, which therefore could make joining easier $[7,8]$. There are reported studies currently in literature on soda lime silicate based glassceramic coatings for titanium oxidation protection [9-11]. However, there is no detailed study for joining of commercially available soda lime silicate glass to titanium in air. This study provides joining of soda lime silicate glass to titanium with a controlled heat treatments in air, investigates effects of heat treatment temperatures

\footnotetext{
*e-mail: mustafa.telli@kocaeli.edu.tr
}

on interfacial reactions between soda lime silicate glass and titanium, models maximal and minimal principal residual stresses developed at joined parts for studied sample dimensions by employing ANSYS 14 multiphysics simulation software and concludes with important points for successful joining of soda lime silicate glass to titanium in air.

\section{Experimental procedure}

Soda lime silicate glass on titanium disk samples were prepared from soda lime silicate glass (Schott Ar glass, Germany) and commercially pure titanium (Alfa Aesar, 99.5 wt.\%). The required pieces were cut from rods by employing a diamond saw and were grinded with 600 and 1000-grade $\mathrm{SiC}$ grinding paper prior to heat treatment. Glass piece was placed on metal piece and inserted directly into the preheated furnace, kept at 700,800 and $900^{\circ} \mathrm{C}$, heat treated for $5 \mathrm{~min}$ in air, cooled down to $550^{\circ} \mathrm{C}$ during $20 \mathrm{~min}$, thermally annealed for $20 \mathrm{~min}$ to remove any joining stress developed in glass due to high-temperature bonding step and finally cooled down to room temperature during $6 \mathrm{~h}$.

Optical and scanning electron microscopy investigations were carried out on cross-sections samples, by sealing the joined samples into polymer mold and by grinding them from a side with 600 and 1000-grade $\mathrm{SiC}$ grinding paper, until the cross section of the glass-to-metal junction was revealed. Optical microscope investigations were done by employing Zeiss Axiotech light microscope with dark field imaging mode. Scanning electron microscope (SEM) investigations were done by employing JEOL 6060 microscope with secondary electron imaging mode. Modeling of residual maximal and minimal principal stresses was done employing ANSYS 14 multiphysics software. Dimensions of disk samples used in calculations were $10 \mathrm{~mm}$ diameter and $2 \mathrm{~mm}$ height for soda lime 
silicate glass and $12.7 \mathrm{~mm}$ diameter and $1.4 \mathrm{~mm}$ height for titanium. Residual stresses were assumed to be developed due to cooling down of bonded glass-titanium joints from thermal stress-relieving annealing step at $550^{\circ} \mathrm{C}$ to room temperature. While glass was modeled using only elastic deformation, titanium was modeled using both elastic and plastic deformation. Table I provides material properties used in the models.

TABLE I

Materials properties used for residual joining stress calculations.

\begin{tabular}{c|c|c}
\hline \hline Materials property & $\begin{array}{c}\text { Soda lime } \\
\text { silicate glass }\end{array}$ & $\mathrm{Ti}$ \\
\hline $\begin{array}{c}\text { Thermal expansion } \\
\text { coeff. } \alpha\left[(\mathrm{m} / \mathrm{m}) /{ }^{\circ} \mathrm{C}\right]\end{array}$ & $9.1 \times 10^{-6}[6]$ & $10.1 \times 10^{-6}[7]$ \\
Young modulus $E[\mathrm{~Pa}]$ & $73 \times 10^{9}[6]$ & $116 \times 10^{9}[7]$ \\
Poison ratio $v$ & $0.22[6]$ & $0.34[7]$ \\
Yield strength $\sigma_{\mathrm{y}}[\mathrm{Pa}]$ & & $240 \times 10^{6}[12]$ \\
True stress $\sigma_{\text {true }}[\mathrm{Pa}]$ at \\
true strain $\varepsilon_{\text {true }}$ of 0.2
\end{tabular}

\section{Results and discussion}

Figure 1 shows that soda lime silicate glass has bonded to titanium without showing any sign of cracking during heat treatment in air. However, as seen from Fig. 1c more clearly, there is some bubble formation for $900^{\circ} \mathrm{C}$ heat treated sample.

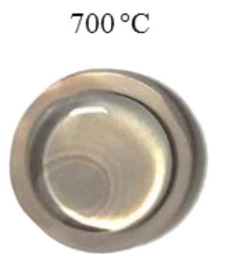

(a)

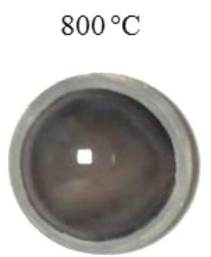

(b)

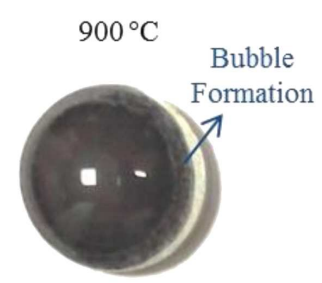

(c)
Fig. 1. Soda lime silicate glass disk on titanium disk samples joined in air for 5 min at heat treatment temperatures of (a) $700{ }^{\circ} \mathrm{C}$, (b) $800{ }^{\circ} \mathrm{C}$ and (c) $900{ }^{\circ} \mathrm{C}$.
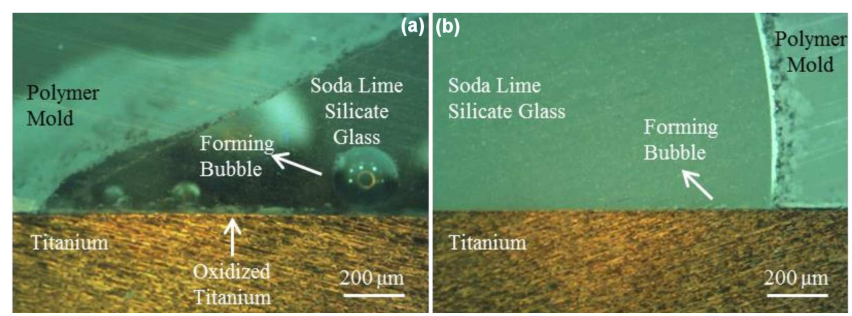

Fig. 2. Optical microscope images of soda lime silicate glass-titanium joining interface taken at $5 \times$ magnification and dark field imaging mode: (a) sample joined at $900^{\circ} \mathrm{C}$ for $5 \mathrm{~min}$ in air, (b) sample joined at $700^{\circ} \mathrm{C}$ for $5 \mathrm{~min}$ in air.

Figure 2 presents optical microscope images, showing joining interface between soda lime silicate glass and titanium that were heat treated at 900 and $700{ }^{\circ} \mathrm{C}$ in air for $5 \mathrm{~min}$. As seen from Fig. 2, there is no micro crack formation in glass at joining interface and no delamination of glass layer from titanium joining interface, illustrating that bonding of glass to titanium was good. However, there was excessive bubble formation at joining interface and titanium oxidation for $900^{\circ} \mathrm{C}$ heat-treated sample, as is clearly seen in Fig. 2a. Figure $2 \mathrm{~b}$ shows that both, bubble formation and oxidation of titanium were decreasing with the decrease in heat treatment temperature to $700{ }^{\circ} \mathrm{C}$.

Figure 3 shows scanning electron microscope image of joining cross section for sample heat treated at $800^{\circ} \mathrm{C}$ for $5 \mathrm{~min}$ in air. As seen in Fig. 3a, bubble formation at joining interface is lower compared to $900^{\circ} \mathrm{C}$ heat treated sample but is still higher than in $700^{\circ} \mathrm{C}$ heat treated sample. Figure $3 \mathrm{~b}$ illustrates that titanium was oxidizing in air and forming oxidized titanium at the interface. It also shows that the bubble formation was happening near the oxidized titanium layer due to its reaction with glass front. Thus, this suggests that bubble formation was related to reaction between oxidized titanium and its reaction with glass at the interface.

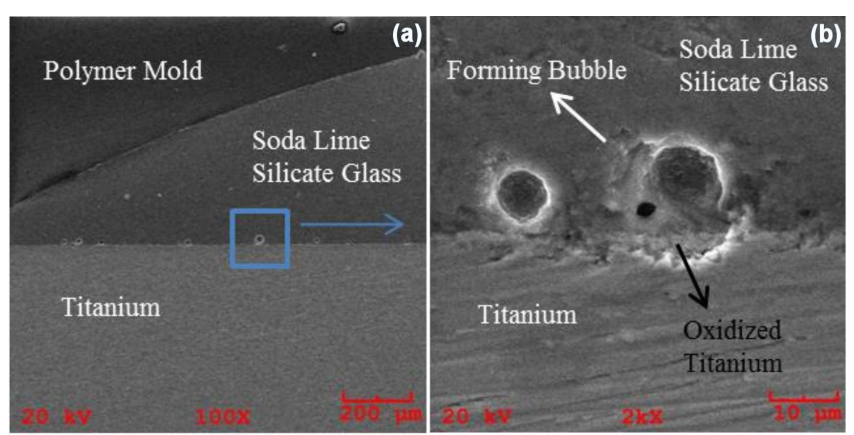

Fig. 3. Scanning electron microscope images of sample heat treated at $800{ }^{\circ} \mathrm{C}$ for $5 \mathrm{~min}$ : (a) low $100 \times$ magnification of cross section sample, (b) higher $2000 \times$ magnification image, showing bubble formation at joining interface.

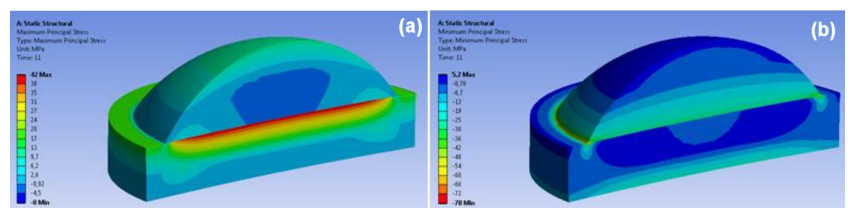

Fig. 4. Residual joining stress levels of soda lime silicate glass-to-titanium junction sample, simulated by employing ANSYS 14 multiphysics simulation software: (a) maximum residual principal stress levels for junction cross section region, (b) minimum residual principal stress levels for junction cross section region.

Figure 4 illustrates modeled residual maximum and minimum principal stress levels of joined samples obtained by employing ANSYS 14 multiphysics software. According to Fig. 4a, joined glass had low residual maximum principal stress levels with the highest levels of the order of $10 \mathrm{MPa}$ observed close to joining interface, 
towards glass outer edge. Figure $4 \mathrm{~b}$ on the other hand shows that residual minimum principle stress levels were slightly higher with the lowest of the order of $-40 \mathrm{MPa}$, observed at glass titanium joining edge, near interface.

Low residual stress levels and good bonding between soda lime silicate glass and titanium was found to be important for successful soda lime silicate glass-titanium joining in air. Simulation results showing low and mainly compressive residual stress levels for glass agree well with experimental findings of absence of cracking or delamination of glass layer. Similar and slightly lower thermal expansion coefficient of glass $\left(9.1 \times 10^{-6}(\mathrm{~m} / \mathrm{m}) /{ }^{\circ} \mathrm{C}\right)$ compared to that of titanium $\left(10.1 \times 10^{-6}(\mathrm{~m} / \mathrm{m}) /{ }^{\circ} \mathrm{C}\right)$ resulted in such low residual stress values. However, there was observed an increasing bubble formation at joining interface with the increase in processing temperatures. In literature, bubble formation was reported to be due $\mathrm{O}_{2}$ release at reaction interface, involving dissolution of titanium oxide into glass and following reaction of silicatebased glass with titanium surface $[11,13]$. Increase in reaction rates leading to $\mathrm{O}_{2}$ gas release at joining interface with an increase of processing temperatures from 700 to $900{ }^{\circ} \mathrm{C}$ could be the reason for observed increasing bubble formation at higher temperatures.

\section{Conclusions}

Soda lime silicate glass-to-titanium joining was successfully achieved in air with heat treatments at 700, 800 and $900{ }^{\circ} \mathrm{C}$ in air. No cracking or delamination of glass layer was observed for any of the joined samples, showing low residual stress levels. ANSYS 14 simulation results suggest (which agrees well with experimental findings) that for the studied sample dimensions, glass experiences mainly low residual minimum stress levels with highest values of the order of $-40 \mathrm{MPa}$ near joining interface at glass-titanium junction. Some bubble formation was observed at glass-titanium joining interface due to reaction. This interfacial reaction was extensive for $900^{\circ} \mathrm{C}$ heat treatment in air. Both optical microscope and SEM investigations have illustrated that bubble formation had decreased with the decrease in heat treatment temperature and was minimal for $700^{\circ} \mathrm{C}$ heat treatment in air. For successful soda lime silicate glass-to-titanium joining in air, interfacial reactions, leading to bubble formation, needed to be minimized by keeping heat treatment temperatures low, around $700^{\circ} \mathrm{C}$. Residual stress levels needed to be kept compressive and low by carefully selecting sample shape and dimensions.

\section{Acknowledgments}

This study was financially supported by scientific research project 2011-70 of Kocaeli University, Turkey.

\section{References}

[1] W.J. Malfait, R. Klemencic, B. Lang, T. Rist, M. Klucka, Z. Zajacz, M.M. Koebel, J. Mater. Process. Tech. 236, 176 (2016).

[2] D.Q. Lei, Z.F. Wang, J. Li, J.B. Li, Z.J. Wang, Renew. Energ. 48, 85 (2012).

[3] C. Chanmuang, M. Naksata, H. Jain, C.E. Lyman, Mater. Sci. Eng. A 474, 218 (2008).

[4] D. Lei, Z. Wang, J. Li, Mater. Design 31, 1813 (2010).

[5] O. Laurent, B. Mantisi, M. Micoulaut, J. Phys. Chem. B 118, 12750 (2014).

[6] F.H. Froes, Titanium: Physical Metallurgy, Processing, and Application, ASM International Materials Park, OH 2015.

[7] Schott tubing brochure for ar-glass, www.schott. com/tubing/english/download/schott-tubing_ brochure_ar-glas_english.pdf.

[8] Pure Ti properties, www.matweb.com/.

[9] Z. Xiao, F. Tan, W. Wang, H. Lu, Y. Cai, X. Qiu, J. Chen, X. Qiao, Ceram. Int. 41, 325 (2015).

[10] T. Moskalewicz, F. Smeacetto, A. CzyrskaFilemonowicz, Surf. Coat. Tech. 203, 2249 (2009).

[11] M. Chen, W. Li, M. Shen, S. Zhu, F. Wang, Corros. Sc. 74, 178 (2013).

[12] S.N. Nasser, W.G. Guo, J.Y. Cheng, Acta Mater. 47, 3705 (1999).

[13] I.W. Donald, P.M. Mallinson, B.L. Metcalfe, L.A. Gerrard, J.A. Fernie, J. Mater. Sci. 46, 1975 (2011). 